\title{
New Measures of Financial Risk, Motivated by Pharmaceutical Research
}

\author{
Anne-Marie Oreskovich ${ }^{*}$, John Gittins \\ Department of Statistics, University of Oxford, Oxford, United Kingdom \\ Email address: \\ anne-marie@post.harvard.edu (Anne-Marie O.), gittins@stats.ox.ac.uk (John G.) \\ ${ }^{*}$ Corresponding author
}

\section{To cite this article:}

Anne-Marie Oreskovich, John Gittins. New Measures of Financial Risk, Motivated by Pharmaceutical Research. International Journal of Economics, Finance and Management Sciences. Vol. 9, No. 1, 2021, pp. 16-28. doi: 10.11648/j.ijefm.20210901.13

Received: March 15, 2019; Accepted: May 5, 2019; Published: February 10, 2021

\begin{abstract}
The paper begins by reviewing the available procedures for measuring value and risk in pharmaceutical research projects. These include Net Present Value (NPV) and its variance, Real Options Valuation (ROV), the Capital Asset Pricing Model (CAPM), Value at Risk (VaR) and Utility. None of these measures focuses specifically on risk as it is perceived by the research manager, except arguably for Utility, which has the serious disadvantage of being by definition a subjective measure. This paper proposes two additional risk measures to go some way towards plugging the gap in what is available. Their advantages are that they: focus on maximum exposure to adverse outcomes, a metric most decision makers have in mind when they wish to evaluate risk; are objective rather than subjective, in contrast to utilities; are easier to specify and more transparent than utilities, since they are in cash terms; are project specific unlike CAPM; satisfy the technical test of coherence, unlike $\mathrm{VaR}$, so it is not possible that diversifying a portfolio could increase the measured risk. The new measures are shown to measure different things from the variance of NPV, which is in some ways similar, and a start is made on exploring what their values are for different patterns of cash flow.
\end{abstract}

Keywords: Resource Allocation, Financial Risk, Risk in Pharmaceutical Research

\section{Introduction}

In the wake of the recent financial crisis, it is clear that efficient and comprehensive financial risk management is of paramount importance across business sectors. Motivated to explore current methods of measuring financial risk in this inclement risk management landscape, the research began with a survey of how financial risk and decision analysis are currently handled in one of the most uncertain and dynamic sectors of business, the pharmaceutical industry.

This particular industry provided an ideal backdrop for us to begin a risk management investigation, as it has long been defined by explosive growth, long drug development timelines, and massive uncertainty. The combined $R \& D$ and market introduction time for a significant product extends over a period of around 12 or 13 years from the first synthesis of a new active substance ("NAS") to the time it is marketed [1]. The average $\mathrm{R} \& \mathrm{D}$ cost for each successful drug is estimated to be approximately $\$ 1.5$ billion [2]. Of all new drugs, only a scant $7 \%$ are profitable [3]. And hence, by their very nature, pharmaceutical drug development projects are inherently risky. Each new chemical entity developed represents a long payback period, many uncertainties, and an extremely low success ratio. It is therefore critical that research and development managers and other pharmaceutical executives have a way to mitigate this risk.

In the course of the research, several pharmaceutical company decision makers were consulted. A common complaint was that project selection was often handled haphazardly, with little quantitative input to the decisions. Many people felt that most project decisions were governed by instinct, business awareness, and a sense of intrinsically important areas that the company "should be" researching. There seemed to be a lack of a highly organized decision-making framework with quantifiable criteria for initial project selection, and then for continuation or termination, and success or failure. Such a framework limits the current struggle with project prioritization, which results in time wasted in advancing low-potential candidates for development and an abundance of under-resourced projects. There is documentation about the research into this area and an 
investigation into what the current literature says about risk management in earlier work [4].

Motivated to try to fix this problem for executives and management both in the pharma industry and in other business sectors, the investigation and analysis began with a look at some canonical risk measures with the pharmaceutical industry as a background. Sections 2 and 3 discuss currently used measures of value and of risk. Section 4 describes the two new risk measures, and makes the case for their use, probably alongside some of the existing measures of value. Section 5 presents a simple example, illustrating the use of the risk measures. Sections 6 and 7 present a theoretical analysis of some of their properties. Sections 8 and 9 are a Conclusion and Bibliography.

\section{Investment Criteria: Net Present Value ("NPV") and Real Options Valuation ("ROV")}

There are many investment criteria that are used both in the pharmaceutical industry, and across many other business sectors. In this section and the next, the main quantitative criteria in current use are examined, and then in Section 4 the two new risk measures are introduced and demonstrated to be a substantial contribution to the area. To begin, two standard ways of evaluating decision scenarios are introduced.

\subsection{NPV}

The NPV of an investment by a company is the sum over time of the resulting cash flows, both positive and negative. Future costs and rewards are discounted at a rate equal to the company's weighted average cost of capital ("WACC") [5]. The commonly referenced NPV rule says that if the NPV is positive, the project or investment should be undertaken, and not otherwise.

\section{2. $\mathrm{ROV}$}

Dixit and Pindyck [6] pointed out the limitations of the NPV rule as it was then typically applied, and proposed a more complete analysis based on ROV theory. ROV is the application of financial options theory to non-financial (real) assets. In this approach, the standard NPV rule is extended to allow for taking decisions at future time points, and in particular for the possibility that irreversible investments may be delayed and perhaps pursued at a later date.

Bode-Greuel [7] introduces a similar measure, which she calls augmented NPV, again as an extension to NPV. ROV as augmented NPV means that NPV is applied dynamically, taking into account that pharma $R \& D$ is structured with key time points or decision nodes, at which senior management and other decision makers decide whether to continue with a project or to abandon it. Dixit and Pindyck [6] call this the Dynamic Programming version of ROV. Decision trees are used to analyze possible outcomes, obstacles, and subsequent managerial options. Risk is captured in probability estimates that are arrived at by using judgment or industry expertise, or by using average attrition rates and industry benchmarks. This methodology is very close to decision analysis, with a particular emphasis on the importance of options which may arise.

\subsection{Capital Asset Pricing Model ("CAPM")}

The CAPM, see for example Brealey, Myers, and Marcus [8], is used to ascertain the rate of return on an investment that is required by a particular market sector, and hence may be used as a means of estimating WACC.

For the stock market as a whole the long run rate of return is higher than it is for government bonds, which are assumed to be risk free. The difference between the two rates is called the market risk premium. It is the additional average return that an investor can expect to receive to compensate for the volatility of stock market prices. Market sectors differ in the extent to which equity prices vary with fluctuations of the stock market as a whole. This dependence is measured by the parameter $\beta$, which is the ratio of the volatility of stock market prices within the sector to average overall volatility. According to CAPM the risk premium required for investment in a given market sector is $\beta$ times the market risk premium. There are of course risks associated with individual companies apart from fluctuations of the overall market index, but these are believed to be avoidable by holding a suitably diversified portfolio of shares. Thus CAPM provides a risk-related rationale for choosing the discount rate to be used in NPV calculations, but only for the risks associated with overall stock market fluctuations.

\section{Measuring and Accounting for Risk}

A description is now given for two canonical ways of evaluating risk, the variance of net present value, and value at risk, together with utility theory, which is a well-known way of assessing decision scenarios so as to take account of risk.

\subsection{Variance of Net Present Value ("Var(NPV)")}

$\operatorname{Var}(\mathrm{NPV})$ is a widely used measure of risk or possible financial exposure. Markowitz [9] was an early and influential advocate. Ross [10] gives a detailed account. A Markowitz Efficient Investment Portfolio is one for which further diversification will not lower the portfolio's risk for a given return expectation (thus no additional expected return can be gained without increasing the risk of the portfolio). The Markowitz Efficient Frontier is the set of all portfolios that will give the highest expected return for each given level of risk or the lowest risk for a given level of expected return.

\subsection{Value at Risk (“VaR”)}

VaR is defined as the value such that the probability of losing more than that amount is a specified probability. For example, if an investment has a 6 -month $3 \% \mathrm{VaR}$ of $\$ 1,500,000$, then there is a $3 \%$ chance that the investment will sustain a loss of more than $\$ 1,500,000$ over 6 months. A more formal definition is as follows [11]:

If $\mathrm{X}$ is a financial position, then $\mathrm{VaR}$ of $\mathrm{X}$ at level $\lambda$ is defined as the amount that must be added to $\mathrm{X}$ such that 


$$
P\left[X+V a R_{\chi}<0\right] \leq \chi \leq P\left[X+V a R_{\chi} \leq 0\right]
$$

There are multiple variations on VaR that are also often used. Two common examples are the following:

\subsubsection{Average Value-at-Risk ("AVaR")}

This is also often called expected shortfall ("ES"): a measure derived from VaR that is more sensitive to the shape of the distribution in the tail. More formally, the AVaR of a random variable $\mathrm{X}$ is defined as the tail expectation (with quantile level $\left.\mathrm{q}_{\lambda}\right)[11]$ :

$$
\operatorname{AVaR}_{\chi}(X)=E\left[-X \mid X \leq q_{\chi}\right]
$$

\subsubsection{Tail Value at Risk ("TVaR")}

This is also often called tail conditional expectation: a measure derived from VaR that evaluates the expectation only in the tail of the distribution. More formally, TVaR at confidence level $p$ of a random variable $\mathrm{X}$ with continuous distribution $\mathrm{F}_{\mathrm{X}}$ is

So that

$$
\operatorname{VaR}\left(\frac{1}{2} X+\frac{1}{2} Y\right)=\frac{1}{2} \operatorname{VaR}(X+Y)>\frac{1}{2}(\operatorname{VaR}(X)+\operatorname{VaR}(Y))=\operatorname{VaR}\left(\frac{1}{2} X\right)+\operatorname{VaR}\left(\frac{1}{2} Y\right)
$$

More generally, a function $f$ on a convex set $\mathrm{S}$ in $\mathrm{R}^{\mathrm{n}}$ is convex if for any $a$ and $b$ in $\mathrm{S}$ and for any $t$ in $[0,1]$,

$$
f(t a+(1-t) b) \leq t f(a)+(1-t) f(b)
$$

As Wozabal notes, this non-convexity of VaR means that the diversification of a portfolio can actually increase the risk as measured by VaR. This is an undesirable incongruity. It means that $\mathrm{VaR}$ is not a coherent measure of risk as defined by Artzner [14]. As Baker [15] notes, this lack of coherence of VaR can lead to questionable investment decisions, which is why the ES is becoming increasingly recommended as a better choice of risk measure.

\subsection{Utility}

Utility is a measure of the attractiveness of an outcome. It refers to the total satisfaction received by someone when choosing a particular good or service; the higher the utility, the more desirable the consequence. Pharma decision managers may assign a utility value to a project to assess its worthiness of development. Utilities have an expectation property which says that the utility of an uncertain prospect is the expectation of the utilities of each of the possible outcomes. For small sums of money this is true with utility equal to monetary value, but a different scale is required when large sums of money are involved, allowing risk aversion to be taken into account. Risk aversion, and therefore utility, varies from person to person. The theory has proved useful to explain some rational choices that contradict the expected monetary value criterion.

\section{Proposed New Risk Measures}

None of the approaches that have been discussed thus far appear to represent a wholly satisfactory procedure for quantifying risk, and now two new measures of risk are proposed. Both measure the maximum financial exposure for a defined as the expected loss of $\mathrm{X}$ conditional upon $\mathrm{X}$ exceeding its $\mathrm{p}^{\text {th }}$ percentile [12]:

$$
\operatorname{TVaR}_{p}(X)=E\left[X \mid X>F_{x^{-1}}(p)\right]
$$

The reader will note that there is a sign difference in the two definitions just given. These are the standard ways of notating these quantities. Here, this inconsistency is simply highlighted, without an attempt to correct this standard usage.

$\mathrm{VaR}$ is a nearly universal risk measure across many business sectors in addition to the pharma industry.

\subsubsection{Lack of Coherence of VaR}

Wozabal et al $[13,18]$ note that VaR is non-convex, since for two portfolios $\mathrm{X}$ and $\mathrm{Y}$ with random values, it could be the case that

$$
\operatorname{VaR}(X+Y)>\operatorname{VaR}(X)+\operatorname{VaR}(Y)
$$

given project or investment program, maximizing over all possible time points. They may be used in conjunction with NPV or augmented NPV valuation procedures.

The first risk measure, called Cash Flow Exposure ("CFE"), is defined as the negative of the minimum over all possible time points of the total net cash flow, up to and including a given time point. This is in other words the maximum over time of the current loss or financial exposure of the investment or project in question.

The second risk measure, called Prospective Cash Flow Exposure, ("PCFE"), is the same, except with the expected future costs less rewards added in.

Together these risk measures are called the Gittins-Oreskovich ("GO”) risk measures.

Both have probability distributions over possible future scenarios. The best single-valued measure of risk is in each case the expectation of maximum financial exposure, and hence of interest is $\mathrm{E}$ (CFE) and $\mathrm{E}$ (PCFE), or ECFE and EPCFE, as they shall be denoted.

The GO risk measures are now introduced more formally:

1) The notation for the minimum of a random variable $X$ is as follows,

$$
\min (X)=\min (x: P(X \leq x)>0)
$$

and for a random process $\mathrm{X}(\mathrm{t})$,

$$
\min _{t}(X(t))=\min \left(X\left(t_{0}\right), X\left(t_{1}\right), X\left(t_{2}\right), \ldots X(T)\right)
$$

Where $t_{0}, t_{1}, t_{2}, \ldots, T$ are the values taken by the time variable t. Similar definitions hold for $\max (\mathrm{X})$ and $\max _{\mathrm{t}}(\mathrm{X}(\mathrm{t}))$.

Assume that all sets of real numbers under consideration have a maximum and a minimum.

2) The net retrospective value at time t, NRV (t), is the net total value of the cash flows up to and including time $t$.

3) The first risk measure CFE is defined to be $-\min _{t}(\mathrm{NRV}$ (t)). 
4) The net future value at time t, NFV (t), is the net total value of all cash flows after time $t$.

5) For any stochastic process $X(t), E X(t)$ is the expectation of $X(t)$. Two examples of this are the following:

1. The expected net future value, $\operatorname{ENFV}(\mathrm{t})$, is the expected net value of all cash flows from time t onwards.

2. The expected net present value at time $t, \operatorname{ENPV}(t)$, is defined as ENPV $(\mathrm{t})=\mathrm{NRV}(\mathrm{t})+\operatorname{ENFV}(\mathrm{t})$.

6) The second risk measure PCFE is defined to be - $\min _{t}$ $(\operatorname{ENPV}(\mathrm{t}))$.

7) The t-dependent values in definitions 2-6 above are all conditional on the history of the project up to time $t$, and are discounted to time $t$ values.

8) The two summary measures of financial exposure are the distributions of CFE and PCFE.

Some notes regarding the above definitions:

NPV refers to the actual and, in general, random outcome with no expectation included. It is assumed, for the moment, that every project in question (and hence every accompanying realization) has both a finite and a discrete timescale. NPV has a probability distribution of values calculated for each possible realization of the decision problem. Note that $\mathrm{NPV}=\mathrm{e}^{-}$ ${ }^{\gamma \mathrm{T}} \mathrm{NRV}(\mathrm{T})$ for $\mathrm{T}=\max (\mathrm{t})$.

The GO risk measures offer five main advantages over other ways of accounting for risk:

1. Firstly, they focus on the maximum exposure, a metric most decision makers have in mind when they wish to evaluate risk. This is a crucial advantage over all other risk measures. They are measuring risk as it impacts the company executive. This is in contrast to NPV, ROV, and VaR, which focus on the interests of the share-holder.

2. They are more objective than utilities. Utilities may be chosen to reflect the decision maker's preferences. They are therefore decision-maker focused, but also vary from one decision maker to another.

3. They are easier to specify and more transparent than utilities, since they are in cash terms whereas utilities are not. It is not obvious how to apply utilities to each of the realizations over time which may occur.

4. They are project-specific, in contrast to the CAPM method, which provides information only about a particular market sector, and not about a specific project.

5. They are coherent, in the Artzner [14] sense of the word, This gives the following:

$$
E N P V=-\$ 1,600,000+\sum_{n=1}^{\infty} \frac{(\$ 200,000)}{(1.1)^{n}}=-\$ 1,600,000+\$ 2,000,000=\$ 400,000
$$

For comparison, now apply the GO risk measures to this simple problem. Using the first risk measure CFE for the case that the price goes up to $\$ 300,000$ after one year (recall that this measure is generated by calculating the net aggregate cash flow unlike VaR.

Artzner et al's definition of coherence refers to the future values of portfolios of securities. In this case, the comparisons are between the cash flow sequences following different investment strategies. Some fairly obvious rejigging of definitions is needed for this difference of setting, and it then follows rapidly that ECFE and EPCFE are coherent measures of risk.

Examples of applications of the GO measures are now provided, followed by an investigation of some of their properties.

\section{Examples}

An example is provided, and then a modification of that example, of how the GO risk measures can be used to approach an investment decision problem. This sample problem has been adapted from an example given by Dixit and Pindyck [6].

\subsection{Example}

Consider a pharmaceutical company that is trying to decide whether to invest in a drug synthesis lab. The investment is completely irreversible - the lab can only be used to make pharmaceutical drugs, and should the market for these chemicals disappear, the company will have lost the entirety of its monetary investment. For simplicity, it is assumed that the lab can be built instantaneously, for $\$ 1,600,000$, and that it will produce one unit of drug required for one course of treatment in a new pharmaceutical drug trial. It is also assumed that the lab will produce this one unit per year forever, with no operating cost. Currently the selling price of this drug compound is $\$ 200,000$, but after one year, the price will change. With probability, it will fall to $\$ 100,000$. The price will remain at this new level forever. A discount rate of $10 \%$ for future cash flows is assumed.

To begin with, suppose that one invests now (at time $t=0$ ). Calculating ENPV (which is NPV in the usual notation), and noting that the expected future price of the drug compound is always

$$
(0.5) \times(\$ 300,000)+(0.5) \times(\$ 100,000)=\$ 200,000(9)
$$

to date at each point in time) results in the following set of values for $\operatorname{NRV}(\mathrm{t})$ :

$$
t=0:-\$ 1,600,000
$$
probability 0.5 , it will rise to $\$ 300,000$, and with equal 


$$
t=4:(1.1) \times(-\$ 1,257,600)+\$ 300,000=-\$ 1,083,360, \text { and so on. }
$$

The minimum value of $\operatorname{NRV}(\mathrm{t})$ is $-\$ 1,600,000$, and hence CFE is $\$ 1,600,000$.

Similarly, for the case that the price goes down to $\$ 100,000$ after one year, the set of values for $\operatorname{NRV}(\mathrm{t})$ are the following:

$$
\begin{gathered}
t=0:-\$ 1,600,000 \\
t=1:-\$ 1,560,000 \\
t=2:-\$ 1,616,000 \\
t=3:-\$ 1,677,600 \\
t=4:-\$ 1,745,360, \text { and so on }
\end{gathered}
$$

In this second case, the values become more negative with each time point after $t=1$, and the downside risk is therefore in principle unlimited. If this scenario were to occur in practice, the simple solution would be to take the realizations as far out timewise as would be reasonable or necessary for that particular decision problem. For example, if a pharma exec requested to know the maximum exposure for this problem, given a time horizon of 10 years, one would simply do the calculations for each time point up to and including $\mathrm{t}=10$, and in this case conclude that the maximum exposure CFE is $\$ 2,320,450$, and occurs at $\mathrm{t}=10$.

After all cases are considered (in this case there are just two, i.e. the price either goes up or it goes down), a cumulative probability distribution for this investment policy (which in this case is to invest immediately, at $t=0$ ) is generated. Noting that each of these cases occurs with probability 0.5 , the probability distribution in this simple example consists of $\$ 1,600,000$ and $\$ 2,320,450$, each with probability 0.5 . (Obviously these probability distributions will rapidly become more complex as more intricate and realistic examples are considered.) It is also noted that in this example,

$$
E C F E=(0.5) \times(\$ 1,600,000)+(0.5) \times(\$ 2,320,450)=\$ 1,960,225 .
$$

whereas - ENPV $=-\$ 400,000$, and hence ECFE $>$ - ENPV.

Now the second risk measure PCFE is applied to this same example for comparison. The reader will recall that this measure is generated by summing the costs and income at each time point, as in the first risk measure, but then adding to this all expected future costs and income, discounted back to that particular time point. For the same investment strategy (invest immediately), and for the case where the price goes up after one year to $\$ 300,000$, the following values of $\operatorname{ENPV}(\mathrm{t})$ occur:

$$
\begin{aligned}
& t=0:-\$ 1,600,000+\frac{\$ 200,000}{1.1}+\sum_{n=2}^{\infty} \frac{(\$ 200,000)}{(1.1)^{n}}=-\$ 1,600,000+\$ 2,000,000=\$ 400,000 \\
& t=1:-\$ 1,760,000+\$ 200,000+\sum_{n=1}^{\infty} \frac{(\$ 300,000)}{(1.1)^{n}}=-\$ 1,560,000+\$ 3,000,000=\$ 1,440,000
\end{aligned}
$$

$$
\begin{aligned}
& t=2:(1.1) \times(\$ 1,440,000)=\$ 1,584,000 \\
& t=3:(1.1)^{2} \times(\$ 1,440,000)=\$ 1,742,400 \\
& t=4:(1.1)^{3} \times(\$ 1,440,000)=\$ 1,916,640
\end{aligned}
$$

exposure PCFE (highest value of $-\operatorname{ENPV}(t)$ ) is - $\$ 400,000$, which occurs at time $\mathrm{t}=0$.

Similarly for the case where the price instead drops to $\$ 100,000$ after 1 year, there are the following values of $\operatorname{ENPV}(\mathrm{t})$ :

As the reader can see, in this case the maximum risk or

$$
\begin{gathered}
t=0:-\$ 1,600,000+\frac{\$ 200,000}{1.1}+\sum_{n=2}^{\infty} \frac{(\$ 200,000)}{(1.1)^{n}}=\$ 400,000 \\
t=1:-\$ 1,760,000+\$ 200,000+\sum_{n=1}^{\infty} \frac{(\$ 100,000)}{(1.1)^{n}}=-\$ 1,560,000+\$ 1,000,000=-\$ 560,000
\end{gathered}
$$

$$
\begin{aligned}
& t=2:(1.1) \times(-\$ 560,000)=-\$ 616,000 \\
& t=3:(1.1)^{2} \times(-\$ 560,000)=-\$ 677,600 \\
& t=4:(1.1)^{3} \times(-\$ 560,000)=-\$ 745,360
\end{aligned}
$$

As one can see, the values become more negative with each time point and the downside risk is therefore in principle

$$
(1.1)^{10-1} \times(-\$ 560,000)=(1.1)^{9} \times(-\$ 560,000)-\$ 1,320,450
$$

Hence CFE here is $\$ 1,320,450$. As before, since each of these cases occurs with probability 0.5 , the probability distribution of PCFE in this simple example therefore consists of - $\$ 400,000$ and $\$ 1,320,450$, both with probability 0.5 .

So EPCFE is 


$$
(0.5) \times(-\$ 400,000)+(0.5) \times(\$ 1,320,450)=\$ 460,225
$$

which is again a greater possible loss than - ENPV = $\$ 400,000$.

\subsection{Modification of the Example}

Next a slightly more complex example is presented in order to illustrate the GO risk measures more fully. Consider the same problem, but now with the investment strategy that one only invests in the project if, after one year, the price goes up to

$\$ 300,000$. Applying the first risk measure to this scenario, the value is 0 if the price goes down to $\$ 100,000$, and if the price goes up to $\$ 300,000$, the values are as follows:

$$
\begin{gathered}
t=0: 0 \text { (we have not yet invested) } \\
t=1:-\$ 1,600,000 \\
t=2:-\$ 1,760,000+\$ 300,000=-\$ 1,460,000
\end{gathered}
$$

As can be seen, in this case the minimum value of $\operatorname{NRV}(t)$ is $-\$ 1,600,000$, which occurs at time $t=1$, and hence CFE is $\$ 1,600,000$. As above, both cases occur with probability 0.5 . In this case, the following results.

$$
E C F E=(0.5) \times(0)+(0.5) \times(\$ 1,600,000)=\$ 800,000
$$

Now applying the second risk measure to this same example for comparison, again there is the value 0 if the price goes down, and if the price goes up, the values are as follows:

$$
\begin{gathered}
t=0: 0+\left[(0.5) \times\left(\frac{1}{1.1}\right) \times\left(-\$ 1,600,000+\sum_{n=1}^{\infty} \frac{(\$ 300,000)}{(1.1)^{n}}\right)\right]=(0.5) \times\left(\frac{1}{1.1}\right) \times(-\$ 1,600,000+\$ 3,000,000)=t= \\
1:-\$ 1,600,000+\sum_{n=1}^{\infty} \frac{(\$ 300,000)}{(1.1)^{n}}=-\$ 1,600,000+\$ 3,000,000=\$ 1,400,000 \\
t=2:(1.1) \times\left(-\$ 1,600,000+\sum_{n=1}^{\infty} \frac{(\$ 300,000)}{(1.1)^{n}}\right)=(1.1) \times(\$ 1,400,000)=\$ 1,540,000 \\
t=3:(1.1)^{2} \times\left(-\$ 1,600,000+\sum_{n=1}^{\infty} \frac{(\$ 300,000)}{(1.1)^{n}}\right)=(1.1)^{2} \times(\$ 1,400,000)=\$ 1,694,000 \\
t=4:(1.1)^{3} \times\left(-\$ 1,600,000+\sum_{n=1}^{\infty} \frac{(\$ 300,000)}{(1.1)^{n}}\right)=(1.1)^{3} \times(\$ 1,400,000)=\$ 1,863,400, \text { and so on }
\end{gathered}
$$

In this case the maximum exposure CFE is $-\$ 636,363$, which occurs at time $t=0$, and as above both cases occur with probability 0.5 . So then

$$
\text { EPCFE }=(0.5) \times(0)+(0.5) \times(-\$ 636,363)=-\$ 318,182
$$

The strategy of waiting to invest for one year and then only investing if the price goes up appears to be the most effective strategy. The NPV rule applied in this instance would recommend that one invests immediately because the expected NPV would be $\$ 400,000$ (as shown in the beginning of this

$$
N P V=(0.5) \times\left(\frac{1}{1.1}\right) \times\left(-\$ 1,600,000+\sum_{n=1}^{\infty} \frac{(\$ 300,000)}{(1.1)^{n}}\right)=\$ 636,363
$$

This strategy also yields a higher ECFE and PCFE, as seen above. This is not surprising and indeed confirms what might be expected: that in this case the value of waiting for further information before making an investment limits the potential risk and is therefore a wise choice. Note too that both ECFE and EPCFE are greater than -ENPV1 in these two examples.

1 Note however that in some cases ECFE $<$-ENPV. This can happen because all the discounting in the calculation of ENPV is to time 0, and this is not true for ECFE. 


\section{Properties of the New Risk Measures}

The following theorem records some important properties of the GO risk measures.

Theorem 1

$$
\text { (i) } C F E \geq-e^{\gamma T} N P V \text { (ii) PCFE } \geq-e^{\gamma T} N P V
$$

Proof.

$$
\begin{gathered}
\text { (i) } C F E=-\min _{t}(N R V(t)) \geq-N R V(T)=-e^{\gamma T} N P V \\
\text { (ii) PCFE }=-\min _{t}(E N P V(t))=-\min _{t}(N R V(t)+E N F V(t)) \geq-N R V(T)=-e^{\gamma T} N P V
\end{gathered}
$$

Corollary. If there is no discounting (i.e. $\gamma=0)$ then $\max (P C F E)=-\min (N P V)$.

Proof.

From (ii), it follows that

$$
\max (P C F E) \geq-\min (N P V)
$$

To complete the proof the reverse inequality must be proved.

Let $R(t)$ denote the realization of the project up to time $t$. Thus, for a given $R(t)$,

$$
\begin{gathered}
N R V(t)+E N F V(t)|R(t) \geq N R V(t)+\min N F V(t)| R(t) \\
=\min (N R V(t)+N F V(t) \mid R(t)) \\
=\min \left(e^{\gamma T} N P V \mid R(t)\right) \\
=\min (N P V \mid R(t))
\end{gathered}
$$

$($ Since $\gamma=0)$

$$
\geq \min (N P V)
$$

The last min being unconditional upon $\mathrm{R}(\mathrm{t})$.

This gives the following:

$$
P C F E=-\min _{t}(N R V(t)+E N F V(t) \mid R(t)) \leq-\min _{t}(N R V(t)+\min N F V(t) \mid R(t)) \leq-\min (N P V)
$$

This is the required reverse inequality and completes the proof of the corollary.

From part (ii) of the theorem it follows that EPCFE $\geq-$ $\mathrm{E}\left(\mathrm{e}^{\gamma \mathrm{T}} \mathrm{NPV}\right)$, so that if $\gamma=0$ then EPCFE $\geq-\mathrm{ENPV}$. This inequality holds with equality in the case of a deterministic sequence of costs and rewards, in which case NPV takes a unique predictable value. Therefore EPCFE + ENPV, with $\gamma$ set equal to 0 , may be regarded as a measure of the risk specifically associated with uncertainty. This is as distinct from the risk inherent in the value of ENPV, the average value of NPV, which also influences $\mathrm{CFE}$ and PCFE. Another measure of the risk

Now

$$
P C F E=-\min [E N P V, N R V(1)=N P V]=\max [0,-N P V]
$$

Note that also

$C F E=\max [-N R V(0),-N R V(1)]=\max [0,-N P V]$

So that $\mathrm{CFE}=\mathrm{PCFE}$ for an AI1G project with $\gamma=0$.

Writing $\mathrm{F}$ for the distribution function of the random variable $\mathrm{X}=\mathrm{NPV}$, it follows that

$$
E P C F E=-\int_{-\infty}^{0} x d F(x)
$$

attributable to uncertainty is sqrt(VarNPV), the standard deviation of NPV. From the definition of EPCFE it follows that $\mathrm{EPCFE}+\mathrm{ENPV}$, with $\gamma=0$, is much closer in meaning to risk as it is commonly understood than is sqrt(VarNPV). Both measures are equal to zero in the absence of uncertainty, but as will be shown, they are not generally equal, and so actually do measure different aspects of risk.

To see this it is sufficient to consider an investment project for which there are just two time points: 0, or before the project begins; and 1, when the project is finished. Call such a project an 'all in one go' or AI1G project, and suppose $\gamma=0$.
Now suppose that NPV has a probability distribution of the form

$$
\mathrm{P}(\mathrm{X}=\mathrm{m})=\mathrm{P}(\mathrm{X}=-\mathrm{m})=\mathrm{p}, \mathrm{P}(\mathrm{X}=0)=1-2 \mathrm{p}
$$

Thus $\mathrm{EX}=0, \operatorname{VarX}=2 \mathrm{pm}^{2}$, and $\mathrm{EPCFE}=\mathrm{pm}$, so that if $\mathrm{p}=$ $1 / 2 \mathrm{~m}^{2}$, then $\operatorname{VarX}=1$ and $\mathrm{EPCFE}=1 / 2 \mathrm{~m}$, and EPCFE takes all values in the interval $(0,0.5]$ as $m$ varies between $\infty$ and 1 , while $\mathrm{ENPV}=\mathrm{EX}$ and $\operatorname{VarNPV}=\operatorname{VarX}$ remain fixed at 0 and 1 
respectively.

\section{Further Properties of the New Risk Measures}

Throughout this section it is assumed that $\gamma=0$.

It has been shown that EPCFE + ENPV like sqrt(VarNPV) is a measure of the risk attributable to uncertainty, but that the two measures are not equivalent to each other. The extent of the variation which can occur in EPCFE while ENPV and VarNPV take the fixed values of 0 and 1 is now explored, starting with the case of an AI1G project as discussed in the previous section.

\subsection{All-In-One-Go (“AIIG”)}

Putting $\mathrm{m}=1$ and $\mathrm{p}=0.5$ gives, as shown above, an AI1G project with $\mathrm{ENPV}=0$, VarNPV $=1$, and $\mathrm{EPCFE}=0.5$. The next theorem shows that this is the largest value of EPCFE (= $\mathrm{ECFE}$ ) for an AI1G project with $\mathrm{ENPV}=0$ and $\operatorname{VarNPV}=1$.
The proof considers alternative distributions over a finite number of values. It seems likely that it could be extended to arbitrary alternative distributions by considering a sequence of approximations to an arbitrary limit distribution, each distribution in the sequence being over a finite number of values.

Theorem 2.

For a random variable $W \in R$ with a discrete distribution over a finite number of values, the maximum value of $E$ ( $\max [0$, $W]$ ) subject to the constraints $E W=0$ and $\operatorname{Var} W=1$, is 0.5 , and occurs when $P(W=1)=P(W=-1)=0.5$.

Before a general proof of Theorem 2 is given, a proof is offered for a restricted case. This is because the proof is easier to follow than the general proof, and it is therefore desirable to build up the reader's confidence by considering this case first.

$\mathrm{M}$ shall be written for $\mathrm{E}(\max [0, \mathrm{~W}])$.

This first proof will involve showing that the proposed solution gives the maximum value of $\mathrm{M}$ for the class $\mathrm{C}$ of random variables. The class $\mathrm{C}$ of random variables $\mathrm{W} \in \mathrm{R}$ are those of the form

$$
\begin{aligned}
& P\left(W=x_{i}\right)=p_{i}, i=1,2,3,4 ; x_{1}=1, x_{2}=-1,1 \neq x_{3}>0,-1 \neq x_{4}<0 \\
& p_{1}+p_{2}+p_{3}+p_{4}=1 \\
& p_{1}-p_{2}+p_{3} x_{3}+p_{4} x_{4}=0 \\
& p_{1}+p_{2}+p_{3} x_{3}^{2}+p_{4} x_{4}^{2}=1 \\
& \text { So }\left(x_{3}^{2}-1\right) p_{3}+\left(x_{4}^{2}-1\right) p_{4}=0 \\
& \text { And } p_{3}=-\left(x_{4}^{2}-1\right) p_{4} /\left(x_{3}^{2}-1\right) \text {. } \\
& \text { Thus } \quad p_{1}+p_{2}=1-p_{3}-p_{4}=1-p_{4}\left(1-\left(\left(x_{4}^{2}-\right.\right.\right. \\
& \text { 1)/( } \left.\left.\left(x_{3}^{2}-1\right)\right)\right) \text {. } \\
& \text { Also } \quad p_{1}-p_{2}=-p_{3} x_{3}-p_{4} x_{4}=-p_{4}\left(x_{4}-\right. \\
& \left.x_{3}\left(\left(x_{4}^{2}-1\right) /\left(x_{3}^{2}-1\right)\right)\right) \text {. } \\
& \text { Hence } \quad\left(2 p_{2}-1\right) / p_{4}=x_{4}-1-\left(x_{3}-1\right)\left(\left(x_{4}{ }^{2}-\right.\right. \\
& \left.1) /\left(x_{3}^{2}-1\right)\right)=\left(x_{4}-1\right)\left(1-\left(x_{4}+1\right) /\left(x_{3}+1\right)\right)= \\
& \left(x_{4}-1\right)\left(\left(x_{3}-x_{4}\right) /\left(x_{3}+1\right)\right) \text {. }
\end{aligned}
$$

Lemma 1. Theorem 2 holds for Class $C$.

Proof:

The constraints $\mathrm{EW}=0$ and $\operatorname{VarW}=1$ may be written as

Also $p_{1}+p_{2}+p_{3}+p_{4}=1$

Note now that

$$
2 M=2\left(p_{1} x_{1}+p_{3} x_{3}\right)=\left(x_{4}-1\right)\left(\frac{x_{3}-x_{4}}{x_{3}+1}\right) p_{4}+1-2 p_{4} x_{4}=1-\left[\left(x_{4}+1\right)\left(\frac{x_{3}+x_{4}}{x_{3}+1}\right)\right] p_{4}
$$

Since $\mathrm{W} \in \mathrm{C}$ and $\left(x_{3}^{2}-1\right) p_{3}+\left(x_{4}^{2}-1\right) p_{4}=0$

It follows that if $p_{4}>0$, then $x_{3}>1<=>x_{4}>-1$, so that

$$
\left(x_{4}+1\right)\left(x_{3}+x_{4}\right)>0
$$

It follows that $M \leq 0.5$ with equality iff $\mathrm{p}_{4}=\mathrm{p}_{3}=0$, and the lemma is proved.

Next the notion of a boundary point is introduced, which will be used in the statement and proof of Theorem 2. A boundary point is a point in the state-space at which at least one of the inequality constraints $(\leq$ or $\geq)$ is satisfied with equality. A simple example is provided by the unit interval $0 \leq x \leq 1$. The points $x$ $=0$ and $\mathrm{x}=1$ are boundary points.

The Lagrange Multiplier Theorem is now introduced. This account can be found in Sawyer [16]. The Theorem has been slightly reworded to suit the purposes of this analysis.

Suppose it is desired to maximize (or minimize) on $\mathrm{R}^{\mathrm{n}}$ a function $\mathrm{f}(\mathrm{X})$,

Where $X=\left(x_{1}, x_{2, \ldots,} x_{n}\right)(1.1 \mathrm{a})$

Subject to $\mathrm{p}$ equality constraints $g_{1}(X)=c_{1}, g_{2}(X)=$ $c_{2}, \ldots, g_{p}(X)=c_{p}(1.1 \mathrm{~b})$

And $\mathrm{q}$ inequality constraints $h_{1}(X) \leq d_{1}, h_{2}(X) \leq$ $d_{2}, \ldots, h_{q}(X) \leq d_{q}(1.1 \mathrm{c})$

The Lagrange Multiplier (LMT).

Assuming appropriate smoothness conditions, at a point in $R^{n}$ which is a maximum off subject to the constraints and is not a boundary point, there are parameter values $\lambda_{1}, \lambda_{2}, \ldots \lambda_{p}$ such that

$$
\partial / \partial x_{i}\left(f(X)+\sum_{j=1}^{p} \chi_{j} g_{j}(X)\right)=0,1 \leq i \leq n
$$

The following well-known theorem will also be needed.

The Extreme Value Theorem ("EVT").

Continuous functions defined on closed bounded regions of $R^{n}$ are bounded and attain their maximum and minimum values.

Proof of Theorem 2.

As above, $\mathrm{M}$ shall be written for $\mathrm{E}$ ( $\max [0, \mathrm{~W}])$.

Let $\mathrm{S}=(\mathrm{m}, \mathrm{n}, \mathrm{X}, \mathrm{Y}, \mathrm{P}, \mathrm{Q})$ denote an arbitrary discrete and finite solution of the constraints, where $X=\left(x_{1}, x_{2}, \ldots, x_{m}\right), Y=\left(y_{1}, y_{2}, \ldots, y_{n}\right), P=$ $\left(p_{1}, p_{2}, \ldots, p_{m}\right), Q=\left(q_{1}, q_{2}, \ldots, q_{n}\right)$,

for

$$
\begin{gathered}
x_{i}>0, p_{i}=P\left(W=x_{i}\right)>0,(i=1,2, \ldots, m) \\
y_{i}>0, q_{i}=P\left(W=-y_{i}\right)>0,(i=1,2, \ldots, n) ;
\end{gathered}
$$




$$
\begin{aligned}
& p=\sum_{i=1}^{m} p_{i}, q=\sum_{i=1}^{n} q_{i}, p+q \leq 1 ; \\
& 1-p-q=P(W=0) \\
& E(W)=p_{1} x_{1}+p_{2} x_{2}+\cdots+p_{m} x_{m}-\left(q_{1} y_{1}+q_{2} y_{2}+\cdots+q_{n} y_{n}\right)=g_{1}(m, n, X, Y, P, Q)=0 \\
& \begin{array}{l}
\text { distribution for the random variable W which satisfies the } \\
\text { constraints). } \\
\text { The constraint equations are: }
\end{array} \\
& \operatorname{Var}(W)=p_{1} x_{1}{ }^{2}+p_{2} x_{2}{ }^{2}+\cdots+p_{m} x_{m}{ }^{2}+q_{1} y_{1}{ }^{2}+q_{2} y_{2}{ }^{2}+\cdots+q_{n} y_{n}{ }^{2}=g_{2}(m, n, X, Y, P, Q)=1
\end{aligned}
$$

Let $\mathrm{V}(\mathrm{S})$ be the solution space formed from $\mathrm{S}$ by keeping $\mathrm{m}$, $\mathrm{n}, \mathrm{P}$, and $\mathrm{Q}$ fixed and allowing $\mathrm{X}$ and $\mathrm{Y}$ to vary, with $\mathrm{x}_{\mathrm{i}} \geq 0$, $(\mathrm{i}=1,2, \ldots, \mathrm{m})$ and $\mathrm{y}_{\mathrm{i}} \geq 0,(\mathrm{i}=1,2, \ldots, \mathrm{n})$. Let $\mathrm{T}=\left(\mathrm{m}, \mathrm{n}, \mathrm{X}^{\prime}, \mathrm{Y}^{\prime}, \mathrm{P}, \mathrm{Q}\right)$ be a point in $\mathrm{V}(\mathrm{S})$ at which $\mathrm{M}$ is maximized. Note that it follows from the EVT that $\mathrm{T}$ exists. Call the maximum value $\mathrm{M}(\mathrm{T})$.

Without loss of generality let $\mathrm{X}^{\prime}=\left(\mathrm{x}_{1}, \mathrm{x}_{2}, \ldots, \mathrm{x}_{\mathrm{m}},{ }^{\prime}, 0,0, \ldots, 0\right)$ and $Y^{\prime}=\left(y_{1}^{\prime}, y_{2}^{\prime}, \ldots, y_{n^{\prime}}^{\prime}, 0,0, \ldots, 0\right)$ where $1 \leq\left(m^{\prime}, n^{\prime}\right) \leq(m, n)$, $\mathrm{x}_{\mathrm{i}}^{\prime}>0\left(\mathrm{i}=1,2, \ldots, \mathrm{m}^{\prime}\right)$, and $\mathrm{y}_{\mathrm{i}}>0\left(\mathrm{i}=1,2, \ldots, \mathrm{n}^{\prime}\right)$. Thus $\mathrm{T} \varepsilon \mathrm{V}^{\prime}(\mathrm{S}) \subset$ $\mathrm{V}(\mathrm{S})$, where $\mathrm{V}^{\prime}(\mathrm{S})$ consists of points of the form (m',n', X', Y',P',Q'), $X^{\prime}$ and $P^{\prime}$ are truncated versions of $X$ and $P$ with just $\mathrm{m}^{\prime}$ ' elements, $\mathrm{Y}^{\prime}$ and $\mathrm{Q}^{\prime}$ are truncated versions of $\mathrm{Y}$ and Q with just n' elements, m', n', P' and Q' are fixed, and X' and

$$
\begin{gathered}
\partial / \partial x_{i}{ }^{\prime}\left(M(T)+\lambda_{1} g_{1}(T)+\lambda_{2} g_{2}(T)\right)=0,1 \leq i \leq m^{\prime} \\
\partial / \partial y_{i}{ }^{\prime}\left(M(T)+\lambda_{1} g_{1}(T)+\lambda_{2} g_{2}(T)\right)=0,1 \leq i \leq n^{\prime}
\end{gathered}
$$

for suitably chosen parameters $\chi_{1}$ and $\chi_{2}$.

Substituting for $g_{1}(T)$ and $g_{2}(T)$ these equations become

$$
\begin{array}{r}
\partial / \partial x_{i}^{\prime}\left[p_{1}{ }^{\prime} x_{1}^{\prime}+p_{2}{ }^{\prime} x_{2}^{\prime}+\cdots+p_{m^{\prime}}{ }^{\prime} x_{m^{\prime}}+\chi_{1}\left(p_{1}{ }^{\prime} x_{1}^{\prime}+\right.\right. \\
p_{2}{ }^{\prime} x_{2}^{\prime}+\cdots+p_{m^{\prime}}{ }^{\prime} x_{m^{\prime}}^{\prime}-\left(q_{1}{ }^{\prime} y_{1}^{\prime}+q_{2}{ }^{\prime} y_{2}^{\prime}+\cdots+\right. \\
\left.\left.q_{n^{\prime}}{ }^{\prime} y_{n^{\prime}}^{\prime}\right)\right)+\chi_{2}\left(p_{1}{ }^{\prime} x_{1}^{\prime 2}+p_{2}{ }^{\prime} x_{2}^{\prime 2}+\cdots+p_{m^{\prime}}{ }^{\prime} x_{m^{\prime}}^{\prime 2}+\right. \\
\left.\left.\left(q_{1}{ }^{\prime} y_{1}^{\prime 2}+q_{2}{ }^{\prime} y_{2}^{\prime 2}+\cdots+q_{n^{\prime}} y_{n^{\prime}}^{\prime 2}\right)\right)\right]=0(71) \\
\partial / \partial y_{i}^{\prime}\left[p_{1}{ }^{\prime} x_{1}^{\prime}+p_{2}{ }^{\prime} x_{2}^{\prime}+\cdots+p_{m^{\prime}}{ }^{\prime} x_{m^{\prime}}^{\prime}+\chi_{1}\left(p_{1}{ }^{\prime} x_{1}^{\prime}+\right.\right. \\
p_{2}{ }^{\prime} x_{2}^{\prime}+\cdots+p_{m^{\prime}} x_{m^{\prime}}^{\prime}-\left(q_{1}{ }^{\prime} y_{1}^{\prime}+q_{2}{ }^{\prime} y_{2}^{\prime}+\cdots+\right. \\
\left.\left.q_{n^{\prime}}{ }^{\prime} y_{n^{\prime}}^{\prime}\right)\right)+\chi_{2}\left(p_{1}{ }^{\prime} x_{1}^{\prime 2}+p_{2}{ }^{\prime} x_{2}^{\prime 2}+\cdots+p_{m^{\prime}} x_{m^{\prime}}^{\prime 2}+\right. \\
\left.\left(q_{1}{ }^{\prime} y_{1}^{\prime 2}+q_{2}{ }^{\prime} y_{2}^{\prime 2}+\cdots+q_{n^{\prime}} y_{n^{\prime}}^{\prime 2}\right)\right]=0(72)
\end{array}
$$

These equations reduce to

$$
\begin{array}{r}
p_{i}{ }^{\prime}+\lambda_{1} p_{i}{ }^{\prime}+2 \lambda_{2} p_{i}{ }^{\prime} x_{i}^{\prime}=0,1 \leq i \leq m^{\prime} \\
-\lambda_{1} q_{j}{ }^{\prime}+2 \lambda_{2} q_{j}{ }^{\prime} y_{j}^{\prime}=0,1 \leq i \leq n^{\prime}
\end{array}
$$

Since $\mathrm{p}_{\mathrm{i}}{ }^{\mathrm{G}} \neq 0 \forall \mathrm{i}$, it follows from equations (i) that at $\mathrm{T}, \mathrm{x}_{\mathrm{i}}{ }^{\prime}=\mathrm{x}_{\mathrm{j}}$ ' $\forall \mathrm{i}, \mathrm{j}$. Since $\mathrm{q}_{\mathrm{i}}{ }^{6} \neq 0 \forall \mathrm{i}$ it also follows from equations (ii) that at $\mathrm{T}$, $\mathrm{y}_{\mathrm{i}}=\mathrm{y}_{\mathrm{j}}, \forall \mathrm{i}, \mathrm{j}$, and the lemma is proved. $\square$

Call the common values $\mathrm{x}$ and $\mathrm{y}$, so that at $\mathrm{T}, \mathrm{x}_{\mathrm{i}}{ }^{6}=\mathrm{x}, 1 \leq \mathrm{i} \leq$ $\mathrm{m}$ ', and $\mathrm{y}_{\mathrm{i}}{ }^{\prime}=\mathrm{y}, 0,1 \leq \mathrm{i} \leq \mathrm{n}$ '. Thus $\mathrm{T} \varepsilon \mathrm{V}$ ''(S), where V'(S) consists of solutions of the form $(1,1, \mathrm{x}, \mathrm{y}, \mathrm{p}, \mathrm{q})$, writing $\mathrm{x}, \mathrm{y}, \mathrm{p}$ and $\mathrm{q}$ in place of the vectors $x(1,1, \ldots, 1)$, etc, and where $p>0, q>0$ and $\mathrm{p}+\mathrm{q} \leq 1$.

To complete the proof of the theorem the following lemma is needed.

Lemma 3. M is maximized for constraint solution points of the form $(1,1, x, y, p, q)$, at the point $U=(1,1,1,1,1 / 2,1 / 2)$, with $M(U)$ $=1 / 2$.

Proof.
$\mathrm{Y}^{\prime}$ are allowed to vary.

Note that $\mathrm{M}(\mathrm{T})$ is maximal in $\mathrm{V}^{\prime}(\mathrm{S})$. Also, $\mathrm{T}$ is not a boundary point of V'(S). This is because the boundary points of V'(S) are defined to be those points at which at least one of the inequality constraints $(\leq$ or $\geq)$ is satisfied with equality, while $\mathrm{T}$ has $\mathrm{x}_{\mathrm{i}}{ }^{\prime}>0$

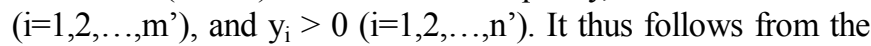
LMT that the Lagrangian partial differential equations hold for $\mathrm{X}^{\prime}$ and $\mathrm{Y}^{\prime}$ at $\mathrm{T}$.

Lemma 2. At the point T, $x_{i}^{\prime}=x_{j}^{\prime} \forall i, j$, and $y_{i}^{\prime}=y_{j}^{\prime} \forall i, j$.

Proof.

The Lagrangian partial differential equations for $\mathrm{X}^{\prime}$ and $\mathrm{Y}$ ' at $\mathrm{T}$ are as follows.

The task is to choose $\mathrm{x}, \mathrm{y}, \mathrm{p}$, and $\mathrm{q}$ so as to maximize $\mathrm{E}[\max (\mathrm{W}, 0)]$ subject to the constraints $\mathrm{E}(\mathrm{W})=0, \mathrm{~V}(\mathrm{~W})=1$, which may be written as maximize px subject to:

$$
p x-q y=0 ; p x^{2}+q y^{2}=1 ; p+q \leq 1
$$

Or equivalently subject to

$$
p x(x+y)=1 ; p\left(1+\frac{x}{y}\right) \leq 1
$$

Eliminating q. These conditions are equivalent to

$$
p x(x+y)=1 ; x y \geq 1
$$

Or simply to

$$
p x(x+1 / x) \leq 1
$$

eliminating $\mathrm{y}$, where $0 \leq \mathrm{p} \leq 1$ and $\mathrm{x}>0$.

To maximize $\mathrm{px}$, it must be the case that $\mathrm{px}(\mathrm{x}+1 / \mathrm{x})=1$, so that $\mathrm{px}=\mathrm{x} /\left(1+\mathrm{x}^{2}\right)$, which is maximized when $\mathrm{x}=1$, so that $\mathrm{p}=$ $1 / 2$. Also, working backwards, $x y=1$, and therefore $y=1$, and $q=$ $1 / 2$ from the original constraint equations. Thus for a maximum $U$ $=(1,1,1,1,1 / 2,1 / 2)$ as required and $\mathrm{M}(\mathrm{U})=\mathrm{px}=1 / 2$ completing the proof of the lemma.

For any discrete and finite solution point $\mathrm{S}, \mathrm{M}(\mathrm{S}) \leq \mathrm{M}(\mathrm{T}) \leq$ $\mathrm{M}(\mathrm{U})=1 / 2$. Now recall that the point $\mathrm{S}$ represents an arbitrary discrete and finite random variable satisfying the constraints, and that $\mathrm{U}$ is the same for all $\mathrm{S}$. This completes the proof of the theorem. $\square$

It follows that for an AI1G project with ENPV $=0$ and VarNPV $=1$ the maximum value of EPCFE is 0.5 , and occurs when $\mathrm{P}(\mathrm{NPV}=1)=\mathrm{P}(\mathrm{NPV}=-1)=0.5$. This follows on substituting - NPV for W.

And in fact Theorem 2 can be proved not just for a real- 
valued discrete finite random variable which satisfies the given conditions, but for any real-valued random variable which satisfies the constraints. For this proof, Professor Colin McDiarmid is thanked.

Generalized Version of Theorem 2.

For any random variable $W \in R$, the maximum value of $E(\max [0, W])$ subject to the constraints $E W=0$ and $\operatorname{Var} W=1$, is 0.5 , and occurs when $P(W=1)=P(W=-1)=0.5$.

Proof.

As in the previous proof, begin with a simple case. Consider a random variable $\mathrm{W}$ that has a two point distribution as follows:

$\mathrm{P}(\mathrm{W}=\mathrm{a})=\mathrm{p}_{\mathrm{a}}>0$

$\mathrm{P}(\mathrm{W}=-\mathrm{b})=\mathrm{p}_{\mathrm{b}}>0$;

$\mathrm{a}, \mathrm{b}>0$;

$\mathrm{p}_{\mathrm{a}}+\mathrm{p}_{\mathrm{b}} \leq 1$

$E W=0: p_{a} a=p_{b} b$

$E W^{2} \leq 1: p_{a} a^{2}+p_{b} b^{2} \leq 1$.

It will be shown that given these constraints, $E[\max (0, W)]=$ $\mathrm{p}_{\mathrm{a}} \mathrm{a} \leq 1 / 2$.

Begin with a change of variables:

Set $\mathrm{z}=\mathrm{p}_{\mathrm{a}} \mathrm{a}>0$. Choose $\mathrm{z}>0, \mathrm{a}, \mathrm{b}>0$.

The next step is to maximize $z$, subject to

$\mathrm{z}(\mathrm{a}+\mathrm{b}) \leq 1$ (from the $\mathrm{EW}^{2} \leq 1$ constraint)

and $z(1 / a+1 / b) \leq 1$ (from the $p_{a}+p_{b} \leq 1$ constraint).

i.e. $z \leq \min \{1 /(a+b), a b /(a+b)\}$.

The aim is to maximize $z$, and hence $a, b>0$ should be chosen to maximize $\min \{1 /(\mathrm{a}+\mathrm{b}), \mathrm{ab} /(\mathrm{a}+\mathrm{b})\}$.

Lemma 4. $\max _{a, b>0} \min [\{1, a b\} /(a+b)]=1 / 2$ and occurs only when $a=b=1$.

Proof.

$\max _{\mathrm{a}, \mathrm{b}>0} \min [\{1, \mathrm{ab}\} /(\mathrm{a}+\mathrm{b})]$

$=\max _{\mathrm{c}>0, \mathrm{a}} \in_{(0, \mathrm{c})} \min [\{1, \mathrm{a}(\mathrm{c}-\mathrm{a})\} / \mathrm{c}]$

$=\max _{\mathrm{c}>0} \min \left[\left\{1, \max _{\mathrm{a}} \mathrm{\epsilon}_{(0, \mathrm{c})}[\mathrm{a}(\mathrm{c}-\mathrm{a})]\right\} / \mathrm{c}\right]$

$=\max _{\mathrm{c}>0} \min \left[\left\{1, \mathrm{c}^{2} / 4\right\} / \mathrm{c}\right]$

$=\max _{\mathrm{c}>0} \min [1 / \mathrm{c}, \mathrm{c} / 4]$

Now $\max _{c>0} \min [1 / \mathrm{c}, \mathrm{c} / 4]=1 / 2$ and occurs only when $\mathrm{c}=2$. This follows immediately by inspection of the graphs for $1 / \mathrm{c}$ and $\mathrm{c} / 4$. Thus at a maximum we have $\mathrm{c}=2$, and $a$ must be chosen to give $\max _{\mathrm{a}} \in_{(0,2)} \min 1 / 2\{1, \mathrm{a}(2-\mathrm{a})\}=1 / 2 \min \left\{1, \max _{\mathrm{a}}[\mathrm{a}(2-\mathrm{a})]\right\}$, which is $1 / 2$ and occurs only when $a=b=1$. $\square$

Now the general case needs to be reduced to the case that was just proved. $\mathrm{W}$ is used to denote the random variable, with $\mathrm{EW}=$ $0, \mathrm{EW}^{2} \leq 1, \mathrm{E}[\mathrm{W} \mid \mathrm{W}>0]=\mu$, and $\mathrm{E}[\mathrm{W} \mid \mathrm{W} \leq 0]=\chi$.

Let $Z=\chi I(W \leq 0)+\mu \mathrm{I}(\mathrm{W}>0)$.

So $\mathrm{EZ}=\mathrm{EW}=0$

$\mathrm{EZ}^{2}=\chi^{2} \mathrm{P}(\mathrm{W} \leq 0)+\mu^{2} \mathrm{P}(\mathrm{W}>0) \leq \mathrm{EW}^{2}=\mathrm{E}\left[\mathrm{W}^{2} \mid \mathrm{W} \leq 0\right] \mathrm{P}(\mathrm{W} \leq$

$0)+\mathrm{E}\left[\mathrm{W}^{2} \mid \mathrm{W}>0\right] \mathrm{P}(\mathrm{W}>0)(67)$

$$
\begin{gathered}
E P C F E=-\left(\frac{1}{(2 \pi)^{1 / 2}}\right) \int_{-\infty}^{0} x \exp \left(-\frac{x^{2}}{2}\right) d x=\left(\frac{1}{(2 \pi)^{1 / 2}}\right) \int_{-\infty}^{0} d\left(\exp \left(-\frac{x^{2}}{2}\right)\right)=\left(\frac{1}{(2 \pi)^{1 / 2}}\right)\left[\exp \left(-\frac{x^{2}}{2}\right)\right]_{-\infty}^{0}=\left(\frac{1}{(2 \pi)^{1 / 2}}\right) \\
\cong \frac{1}{2.5066} \cong 0.3989 .
\end{gathered}
$$

Note that here, as in the following cases that will be considered, $\mathrm{PCFE}=\mathrm{CFE}$, since $\mathrm{ENFV}=0$ at all event nodes. (And hence $\mathrm{EPCFE}=\mathrm{ECFE}$.)

2. Two independent normally distributed rewards

Now suppose $\mathrm{X}$ and $\mathrm{Y}$ are independently distributed random
This last inequality holds with equality only if $\mathrm{W} \mid \mathrm{W} \leq 0$ and $\mathrm{W} \mid \mathrm{W}>0$ are constants. Call this condition $(*)$. (Here we are making use of the general result that for any real-valued random variable $Z$ whose variance exists, $\operatorname{Var}(Z)=E\left(Z^{2}\right)-(E(Z))^{2} \geq 0$, and $=0$ only if $Z$ is a constant.)

Also $\mathrm{E}[\max (\mathrm{W}, 0)]=\mathrm{E}[\max (\mathrm{Z}, 0)]=\mu \mathrm{P}(\mathrm{W}>0)$. It follows that given any $\mathrm{W}$ for which $\mathrm{EW}=0, \mathrm{EW}^{2}=1$, and $(*)$ does not hold, there is a $\mathrm{W}^{\prime}$ with $\mathrm{EW}^{\prime}=0, \mathrm{EW}^{, 2}=1, \mathrm{E}\left[\max \left(\mathrm{W}^{\prime}, 0\right)\right]>$ $\mathrm{E}[\max (\mathrm{W}, 0)]$, and for which $(*)$ does hold.

To see this note that if $(*)$ does not hold, then $\mathrm{EZ}^{2}<\mathrm{EW}^{2}=1$, so that $\mathrm{EZ}^{2}<1$. In the above, one needs to let $\mathrm{W}^{\prime}=$ $\mathrm{Z} / \operatorname{sqrt}\left(\mathrm{E}\left(\mathrm{Z}^{2}\right)\right)$, so that $\mathrm{E}\left[\max \left(\mathrm{W}^{\prime}, 0\right)\right]$ = $\left[1 / \operatorname{sqrt}\left(\mathrm{E}\left(\mathrm{Z}^{2}\right)\right)\right] \mathrm{E}[\max (\mathrm{W}, 0)]$. If $(*)$ does not hold, then $\left[1 / \operatorname{sqrt}\left(E\left(Z^{2}\right)\right)\right]>1$, and hence $E\left[\max \left(\mathrm{W}^{\prime}, 0\right)\right]>E[\max (\mathrm{W}, 0)]$.

From the first part of the proof, it further follows that $\mathrm{W}=+/$ 1 with probabilities $(1 / 2,1 / 2)$ gives the unique maximum of $\mathrm{E}[\max (\mathrm{W}, 0)]$, and the theorem is proved.

\subsection{All in n Goes (“AInG”)}

Now several variations to the AIIG case that was considered normal random variable cases, and then progress to Bernoulli random variable cases.

Similar notation as above will be used, except that since more than one "go's" are now being considered, there will be not just a random variable (and reward), but now successive rewards for stages $\mathrm{i}=1,2, \ldots$, etc. These rewards will be represented by letters such as $\mathrm{X}, \mathrm{Y}$, and $\mathrm{Z}$ for random rewards, and $\mathrm{x}, \mathrm{y}$, and $\mathrm{z}$ for particular values. This nomenclature works (without subscripts) as long as there are not too many stages. For the case of $n$ stages discussed below, subscripts are introduced.

\subsubsection{Normally Distributed Rewards}

1. One standard normal reward $(A I I G)$

Recall that for the case of AI1G, for a random NPV $=X$,

$$
E P C F E=-\int_{-\infty}^{0} x d F(x)
$$

The probability density function for a normal random variable $\mathrm{X}$ with mean $\mu$ and standard deviation $\sigma$ is

$$
\left(\frac{1}{\sigma(2 \pi)^{1 / 2}}\right) \exp \left(-1 / 2((x-\mu) / \sigma)^{2}\right)
$$

If $\mathrm{X} \sim \mathrm{N}(0,1)$, then

variables with $\mathrm{X}, \mathrm{Y} \sim \mathrm{N}(0,1 / 2)$ (this ensures that $\mathrm{ENPV}=0$ and $\operatorname{VarNPV}=1) . \mathrm{PCFE}=-\min [0, \mathrm{X}, \mathrm{X}+\mathrm{Y}]$.

There are three cases to consider: 0 is the minimum, $\mathrm{X}$ is the minimum, and $\mathrm{X}+\mathrm{Y}$ is the minimum.

Case 1: If 0 is the minimum, then both $\mathrm{X}$ and $\mathrm{X}+\mathrm{Y}$ are $\geq 0$. above will be discussed. The discussion will begin with three 
Case 2: If $\mathrm{X}$ is the minimum, then $\mathrm{X} \leq 0$, and $\mathrm{X}+\mathrm{Y} \geq \mathrm{X}$ which means $\mathrm{Y} \geq 0$.

Case 3: If $\mathrm{X}+\mathrm{Y}$ is the minimum, then $\mathrm{X}+\mathrm{Y} \leq 0$, and $\mathrm{X}+\mathrm{Y}$ $\leq \mathrm{X}$ which means $\mathrm{Y} \leq 0$.

The contribution of each case to EPCFE will now be computed (and the contributions summed):

Case 1: 0

Case 2: In this case, $\mathrm{X} \leq 0$ and hence we must integrate $\mathrm{xdF}(\mathrm{x})$ from $-\infty$ to 0 . Also $\mathrm{Y} \geq 0$ and the probability of this is $1 / 2$. Hence

$$
-1 / 2 \int_{-\infty}^{0} x d F(x)=-1 / 2\left(\frac{1}{(2 \pi * 1 / 2)^{1 / 2}}\right) \int_{-\infty}^{0} x \exp \left(-x^{2}\right) d x=-1 / 2\left(\frac{1}{\pi^{1 / 2}}\right)\left[1 / 2 \exp \left(-x^{2}\right)\right]_{-\infty}^{0}
$$

$=\left(\frac{1}{4 \pi^{1 / 2}}\right)$ as the contribution to EPCFE for this case.

Case 3: In this case, there are two subcases to consider: $\mathrm{X}, \mathrm{Y}$ $\leq 0$, and $X \geq 0, Y \leq-X$.

$\mathrm{X}, \mathrm{Y} \leq 0$ :

This subcase gives

$$
-\int_{-\infty}^{0} \int_{-\infty}^{0}(x+y) d F(x) d F(y)
$$

(since the integration must be taken over all negative values for both variables). $\mathrm{X}$ and $\mathrm{Y}$ have the same distribution, so this is equivalent to

$$
\begin{aligned}
&-\int_{-\infty}^{0} \int_{-\infty}^{0} 2 x d F(x) d F(y)=-\int_{-\infty}^{0} x d F(x)=\frac{1}{2 \pi^{1 / 2}} \\
&=-\int_{0}^{\infty}\left[x \phi\left(-(2 x)^{1 / 2}\right)+\left(\frac{1}{2(\pi)^{1 / 2}}\right)\left[-\exp \left(-y^{2}\right)\right]_{-}^{-x}\right] d F(x)=\left(\frac{1}{\pi^{1 / 2}}\right) \exp \left(-x^{2}\right) d x \\
&=-\int_{0}^{\infty}\left[x \phi\left(-(2 x)^{1 / 2}\right)-\left(\frac{1}{2(\pi)^{1 / 2}}\right)\left[\exp \left(-x^{2}\right)\right]\right] d F(x) \\
&=-\int_{0}^{\infty}\left[x \phi\left(-(2 x)^{1 / 2}\right)-\left(\frac{1}{2(\pi)^{1 / 2}}\right)\left[\exp \left(-x^{2}\right)\right]\right]\left(\frac{1}{\pi^{1 / 2}}\right) \exp \left(-x^{2}\right) d x
\end{aligned}
$$

Where

$\mathrm{X} \geq 0, \mathrm{Y} \leq-\mathrm{X}$

This subcase gives

$$
-\int_{0}^{\infty} \int_{-\infty}^{-x}(x+y) d F(x) d F(y)
$$

(Since the integration must be taken over all positive values of $\mathrm{X}$ and all values for which $\mathrm{Y} \leq-\mathrm{X})$.

Then

$$
-\int_{0}^{\infty} \int_{-\infty}^{-x}(x+y) d F(x) d F(y)
$$

To evaluate this remaining integral, the two pieces of the integral will be considered separately. To evaluate the first piece $-\int_{0}^{\infty} x \phi\left(-(2 x)^{1 / 2}\right)\left(\left(\frac{1}{\pi^{1 / 2}}\right) \exp \left(-x^{2}\right) d x\right)$

Note that

$$
\begin{gathered}
-\int_{0}^{\infty} 2 x \phi\left(-2^{1 / 2} x\right)\left(\exp \left(-x^{2}\right) d x=-\int_{0}^{\infty} \phi\left(-2^{1 / 2} x\right) d\left(\exp \left(-x^{2}\right)\right)\right. \\
=-\left[\phi\left(-2^{1 / 2} x\right) \exp \left(-x^{2}\right)\right]_{0}^{\infty}-\int_{0}^{\infty} 2^{1 / 2} \phi\left(-2^{1 / 2} x\right) \exp \left(-x^{2}\right) d x \\
=1 / 2-\left(\frac{2^{1 / 2}}{(2 \pi)^{1 / 2}}\right) \int_{0}^{\infty} \exp \left(-2 x^{2}\right) d x \\
=1 / 2-2^{1 / 2} / 4=1 / 2\left(1-2^{1 / 2} / 2\right) .
\end{gathered}
$$

To evaluate the second piece Putting these two pieces together then gives

$-\int_{0}^{\infty}-1 / 2(\pi)^{1 / 2}\left[\exp \left(-x^{2}\right)\right]\left(\frac{1}{\pi^{1 / 2}}\right) \exp \left(-x^{2}\right) d x$

Note also that $\left(\frac{1}{\left(2 \pi \sigma^{2}\right)^{1 / 2}}\right) \int_{0}^{\infty} \exp \left(-x^{2} / 2 \sigma^{2}\right) d x=1 / 2$, so

$$
\begin{gathered}
-\int_{0}^{\infty}\left[x \phi\left(-(2 x)^{1 / 2}\right)-1 / 2(\pi)^{1 / 2}\left[\exp \left(-x^{2}\right)\right]\left(\frac{1}{\pi^{1 / 2}}\right) \exp \left(-x^{2}\right)\right] d x \\
=\left(\frac{-1}{4 \pi^{1 / 2}\left(1-2^{1 / 2} / 2\right)}\right)+\left(\frac{1}{4(2 \pi)^{1 / 2}}\right) \quad=\left(\frac{1}{4 \pi^{1 / 2\left(2^{1 / 2}-1\right)}}\right) \text { as the contribution to EPCFE of this case. } \\
\text { These contributions all sum to the following total: }
\end{gathered}
$$
$\mathrm{EPCFE} \cong 0.4816$. 


\section{3. $n$ independent identically distributed rewards}

The notation used above for $\mathrm{X}$ and $\mathrm{Y}$ is changed here, and instead subscripts are introduced. Suppose $Z_{1}, Z_{2}, \ldots, Z_{n}$ are independently distributed random variables with $Z_{1}, Z_{2}, \ldots, Z_{n} \sim$ $\mathrm{N}(0,1 / \mathrm{n})$ (again to ensure that ENPV $=0$ and $\operatorname{VarNPV}=1$ ).

$$
P C F E=-\min \left(0, Z_{1}, Z_{1}+Z_{2}, \ldots, Z_{1}+Z_{2}+\cdots+Z_{n}\right)
$$

In the limit as $n$ approaches $\infty, P C F E=\min _{0 \leq t \leq 1} Z(t)$, where $\mathrm{Z}(\mathrm{t})$ is standard Brownian motion. Writing $\mathrm{X}=$ PCFE yields

$$
\begin{aligned}
& 1-F_{X}(x)=P(P C F E \geq x)=P\left(\max _{0 \leq t \leq 1} Z(t)>x\right) \\
& =\frac{2}{(2 \pi)^{1 / 2}} \int_{X}^{\infty} \exp \left(-\frac{y^{2}}{2}\right) d y(x>0)=2 \phi(-x)
\end{aligned}
$$

Where the second to last equality is a standard identity for Brownian motion; see for example Ross [17].

The general result that for a continuous positive random variable $\mathrm{Z}$,

$$
E(Z)=\int_{0}^{\infty}\left(1-F_{z}(z)\right) d x
$$

gives the following:

$$
\left.E P C F E=\int_{0}^{\infty} 2 \phi(-x) d x=\frac{2^{1 / 2}}{(\pi)}\right)=0.7979 .
$$

This is because

$$
\begin{aligned}
& \begin{array}{c}
\int_{0}^{\infty} \phi(-x) d x=[\phi(-x) x]_{0}^{\infty} \\
+\frac{1}{(2 \pi)^{1 / 2}} \int_{0}^{\infty} \exp \left(-\frac{x^{2}}{2}\right) x d x
\end{array} \\
& \begin{array}{c}
\int_{0}^{\infty} \phi(-x) d x=[\phi(-x) x]_{0}^{\infty} \\
+\frac{1}{(2 \pi)^{1 / 2}} \int_{0}^{\infty} \exp \left(-\frac{x^{2}}{2}\right) x d x
\end{array} \\
& =-\left\{0 \text { if } X=Y=\left(\frac{1}{2^{1 / 2}}\right) ;\left(\frac{-1}{2^{1 / 2}}\right) \text { if } X=\left(\frac{-1}{2^{1 / 2}}\right) \text { and } Y=\left(\frac{1}{2^{1 / 2}}\right) ; 0 \text { if } X=\left(\frac{1}{2^{1 / 2}}\right) \text { and } Y=\left(\frac{-1}{2^{1 / 2}}\right) ; 2\left(\frac{-1}{2^{1 / 2}}\right) \text { if } X=Y\right. \\
& \left.=\left(\frac{-1}{2^{1 / 2}}\right)\right\} \text {. } \\
& P C F E=-\min [0, X, X+Y]
\end{aligned}
$$

Thus EPCFE $=\mathrm{E}(\mathrm{PCFE})=1 / 4(-0)+1 / 4\left(2^{-1 / 2}\right)+1 / 4(-0)+1 / 4\left(2 * 2^{-}\right.$ $1 / 2)=3 / 4\left(2^{-1 / 2}\right)=0.5303$.

3. Three stages.

Let $\mathrm{X}, \mathrm{Y}$, and $\mathrm{Z}$ be independently identically distributed random variables with $\mathrm{P}(\mathrm{X}=\mathrm{r})=\mathrm{P}(\mathrm{X}=-\mathrm{r})=1 / 2$. Now $\operatorname{Var}(\mathrm{X}+\mathrm{Y}+\mathrm{Z})=1=3 \operatorname{Var}(\mathrm{X})=3 \mathrm{r}^{2}$, so $\mathrm{r}=3^{-1 / 2}$. $\mathrm{PCFE}=-\min [0$, $\mathrm{X}, \mathrm{X}+\mathrm{Y}, \mathrm{X}+\mathrm{Y}+\mathrm{Z}]$. A quick sketch of an event tree shows that there are 8 possible pathways through the tree. For example, let +++ signify the path for which $X=Y=Z=r$. For this path, $\mathrm{PCFE}=-\min [0, \mathrm{X}, \mathrm{X}+\mathrm{Y}, \mathrm{X}+\mathrm{Y}+\mathrm{Z}]=-\min [0, \mathrm{r}, \mathrm{r}+\mathrm{r}, \mathrm{r}+\mathrm{r}+\mathrm{r}]=$ 0 . The values for PCFE and associated probabilities are as follows: 0 with probability $3 / 8$; $r$ with probability $3 / 8 ; 2 \mathrm{r}$ with probability $1 / 8 ; 3 \mathrm{r}$ with probability $1 / 8$. Hence $\mathrm{EPCFE}=8(\mathrm{r} / 8)=$ $3^{-1 / 2}=0.5774$.

4. Four stages.

A similar analysis gives EPCFE $=19(\mathrm{r} / 16)=19\left(4^{-1 / 2}\right) / 16=$ using integration by parts. And this is equal to

$$
\frac{-1}{(2 \pi)^{1 / 2}}\left[\exp \left(-\frac{x^{2}}{2}\right)\right]_{0}^{\infty}=\frac{1}{(2 \pi)^{1 / 2}}
$$

Therefore $\mathrm{EPCFE}=0.3989,0.4816$, and 0.7979 for the cases of 1,2 , and an infinite number of normally distributed rewards, respectively. This is probably because as the number of stages increases, the scope for large values of PCFE to occur by chance widens as well.

\subsubsection{Bernoulli Case}

The analysis is extended now to include the possibility that the rewards have a Bernoulli distribution, instead of the normal distribution considered above. AInG cases (for $n=1,2,3,4$, and 5) are considered. Since as above incremental rewards with mean 0 are being used, here $\mathrm{PCFE}=\mathrm{CFE}$ and hence $\mathrm{EPCFE}=$ ECFE.

\section{One stage.}

For some $r \in R$, let $X$ be a random reward with $P(X=r)=$ $P(X=-r)=1 / 2, E(X)=0$, and $\operatorname{Var}(X)=1$. Thus $\operatorname{Var}(X)=r^{2}$, so $r$ $=1$.

$$
P C F E=-\min [0, X]=-\{0 \text { if } X=1 ;-1 \text { if } X=-1\}
$$

Thus EPCFE $=\mathrm{E}(\mathrm{PCFE})=1 / 2(-0)+1 / 2(1)=1 / 2$. (Note that it is still true that $\mathrm{ENPV}=0$ and $\operatorname{VarNPV}=1$.)

2. Two stages.

For some $\mathrm{r} \in \mathrm{R}$, let $\mathrm{X}$ and $\mathrm{Y}$ be independently and identically

\subsection{8 .}

5. Five stages.

A similar analysis gives $\mathrm{EPCFE}=44(\mathrm{r} / 32)=44\left(5^{-1 / 2}\right) / 32=$ 0.6149 .

The increase in EPCFE with an increase in the number of stages that was observed for normally distributed rewards holds here as well. The Central Limit Theorem ("CLT") states that the mean of a large number of independent and identically distributed random variables, each with finite mean and variance, is approximately normally distributed. It follows that this case also tends to standard Brownian motion as the number of stages tends to infinity, with EPCFE $=0.7979$.

\section{Conclusion}

Two new financial risk measures are proposed (the GO 
measures). They are based on cash flow exposure and are particularly suitable for resource allocation decisions within a company. Theoretical analysis shows that they describe significant aspects of decision scenarios which are not covered by the established alternatives. Numerical examples show how they would work in practice.

An important objective now is to explore further the types of project which perform well in terms of these measures, and those which perform badly, to improve the intuitive understanding. Further investigation is also required of how best to incorporate GO calculations into project management software, either by writing new software or by adding to the functionality of existing products.

The strategies for risk reduction currently in use vary considerably in their effectiveness, with some companies employing effective risk mitigation strategies, and some in great need of procedures for risk realignment. Hopefully the GO measures will be of interest in pharmaceutical research and more widely.

\section{References}

[1] European Federation of Pharmaceutical Industries and Associations. (2012) The Pharmaceutical Industry in Figures. Key Data 2012. http://www.efpia.eu/sites/www.efpia.eu/files/EFPIA_Figures_201 2 Final-20120622-003-EN-v1.pdf.

[2] Mestre-Ferrandiz, J., Sussex, J., and Towse, A. (2012) The R\&D Cost of a New Medicine. Office of Health Economics. London.

[3] Gavura, S. (2012) What Does a New Drug Cost? Part II: The Productivity Problem. Science-Based Medicine. $\mathrm{http}: / /$ www.sciencebasedmedicine.org/index.php/what-does-anew-drug-cost-part-ii-the-productivity-problem/.

[4] Oreskovich, A and Gittins, J. C. (2016) The Evaluation of Risk in Pharmaceutical Research: A Study of Current Models and Techniques. R\&D Management. 46 (5): 900-913.

[5] Dixit, A. K., and Pindyck, R. S. (1995) The Options Approach to Capital Investment. Harvard Business Review, 73 (3), 105-115.
[6] Dixit, A. K., and Pindyck, R. S. (1994) Investment Under Uncertainty. Princeton and Chichester: Princeton University Press.

[7] Bode-Greuel, K. M. (2000) Real Options Evaluation in Pharmaceutical R\&D: A New Approach to Financial Project Evaluation. Scrip Reports, Strategic Management Series. 2, 1144.

[8] Brealey, R., Myers, S., and Marcus, A. (2004) Fundamentals of Corporate Finance. New York: McGraw-Hill.

[9] Markowitz, H. (1952) Portfolio Selection. Journal of Finance, 7, 77-91.

[10] Ross, S. (2003) An Elementary Introduction to Mathematical Finance: Options and Other Topics. New York: Cambridge University Press.

[11] El Karoui, N. (2005) Value at Risk and Average Value at Risk. ChaireUnesco Tunis. October 2005.

[12] Tsanakas, A. (2005) Section 5.5 of Enterprise Risk Modelling Notes. Support pages for courses taught at Cass Business School, City University, London by Andreas Tsanakas. $\mathrm{http}: / /$ casserm.wordpress.com/lecture-notes/5-measuring-riskand-performance/55-properties-of-tail-value-at-risk/.

[13] Wozabal, D. (2010) A New Method for Value-at-Risk constrained optimization using the Difference of Convex Algorithm. Working Paper.

[14] Artzner, P., Delbaen, F., Eber, J., and Heath, D. (1999) Coherent Measures of Risk. Mathematical Finance, 9 (3), 203-228.

[15] Baker, R. (2010) Risk Aversion in Maintenance: a Utility-Based Approach. IMA Journal of Management Mathematics. 21 (4), 319-332.

[16] Sawyer, S. (2002) The Method of Lagrange Multipliers. $\mathrm{http}: / /$ xbeams.chem.yale.edu/ batista/vaa/LagrangeMult.pdf.

[17] Ross, S. (1983) Stochastic Processes. New York: Wiley.

[18] Wozabal, D., Hochreiter, R., and Pflug, G. (2010) A D. C. Formulation of Value-at-Risk Constrained Optimization. Optimization, 59 (3), 377-400. 